\title{
A study on important factors influencing on the success of human resources management
}

\author{
Mostafa Mahouti $^{\mathrm{a}^{*}}$, Masoumeh Sadat Abtahi ${ }^{\mathrm{b}}$ and Ahmad Sardari ${ }^{\mathrm{c}}$
}

${ }^{a}$ Department of Management, Qazvin Branch, Islamic Azad University, Qazvin,Iran

${ }^{b}$ Department of Humanities, Zanjan Branch, Islamic Azad University, Zanjan, Iran

${ }^{c}$ Department of Management, Shahed University, Tehran, Iran

\section{CHRON I C LE}

\section{Article history:}

Received October 28, 2013

Received in revised format

25 November 2013

Accepted 29 January 2014

Available online

February 72014

Keywords:

Human resources management

Responsibility

Excellence

Innovation

\section{A B S T R A C T}

This paper investigates the effects of three factors of courtesy, generosity and responsibility on human resources development (HRM) in one of Iranian auto industries based on Yoon method [Yoon, C. (2009). The effects of organizational citizenship behaviors on ERP system success. Computers in Human Behavior, 25(2), 421-428.]. The study considers whether having a good sense of responsibility improves the quality of information in HRM. It also investigates whether having good courtesy as well as excellence improve HRM and finally the study investigates the effect of excellence on improving innovation in the area of information technology. Using structural equation modeling, the study confirms all hypotheses of the survey and the implementation of Freedman test confirms that courtesy plays the most important effect followed by having a good generosity and responsibility.

\section{Introduction}

Human resources development (HRM) is located at the heart of economic and business development and it is considered as a primary component for reaching sustainable development objectives. HRM has been defined as empowering employees by fostering the contributory capacities that they can contribute on enterprises. Over the years, the concept of HRM has evolved from solely concentrating on individual capacity to build institutional capacity at the national level, through socio-economic policies and development plan and strategies (Wells \& Schminke, 2001). HRM is stated as facilitating the development of national human capacities to reach sustainable, inclusive, equitable development. Information and communication technology (ICT) is one of the most important sectors for the socio-economic development in most countries. The necessity to enhance skills for emerging

*Corresponding author.

E-mail addresses: $\underline{m}$ almasi2020@yahoo.com (M. Mahouti) 
sectors including green growth, knowledge economy, intellectual property policy evaluation and management, etc. has become important in developing countries.

A comprehensive, cross and integrated HRM program that is sensitive to gender considerations and attuned to specific requirements of vulnerable population must be adopted, incorporating different things such as communications, education and training, science and technology, and employment. Ethical attitudes are essential parts of HRM and there are many studies associated with this aspect. Adebayo (2005) investigated the moderating effects of perceived organizational support and public recognition in association between unethical attitudes and pro-social behavior among a sample of Nigeria police officers. They reported an inverse relationship between unethical attitudes and prosocial behavior among police officers with high or average levels of perceived organizational support and public recognition, while they reported a positive relationship between unethical behavior and pro-social behavior among police officers with low perceived organizational support and public recognition.

Vardaman et al. (2014) performed an investigation on pro-social rule breaking (PSRB) by conceptualizing this behavior as an ethical decision requiring tradeoffs and ethical assessments. They presented a model of PSRB, which contextualized the behavior and offered a set of propositions, which investigates the role of each climate type on PSRB. Van Buren III et al. (2011) critiqued the shift from employee concentration to strategy focus in the role of HRM. Cash (2012) discussed corporate social responsibility and petroleum development in sub-Saharan Africa. Campbell (2012) investigated the role of Corporate Social Responsibility (CSR), recommending the usefulness of using a holistic and historical perspective. It underlines the relative importance of considering the evolving regulatory frameworks within which mining activities happen to consider the changing roles played by the different actors involved, whether multilateral, national or local, public or private. Aslan and Şendoğdu (2012) investigated the correlation between ethical leadership, corporate ethical values, ethical behavior and corporate social responsibility in Turkey. They concluded that ethical leadership influences corporate social responsibility positively, and social responsibility in turn influences corporate ethical values and behaviors positively.

\section{The proposed study}

This paper investigates the effects of three factors of courtesy, generosity and responsibility on human resources development (HRM) in one of Iranian auto industries based on Yoon method (Yoon, 2009). The study considers whether having a good sense of responsibility improves the quality of information in HRM. It also investigates whether having good courtesy as well as excellence improve HRM and finally the study investigates the effect of excellence on improving innovation in the area of information technology. Therefore, we consider the following four hypotheses,

1. There is a positive relationship between having a good sense of responsibility and quality of HRM.

2. There is a positive relationship between generosity and improvement on efficiency of HRM.

3. There is a positive relationship between courtesy and improvement on efficiency of HRM.

4. There is a positive relationship between courtesy and tendency to have innovated ideas.

The proposed study has been implemented among the regular employees of one of Iranian automakers.

$$
n=\frac{N \times z_{\alpha / 2}^{2} \times p \times q}{\varepsilon^{2} \times(N-1)+z_{\alpha / 2}^{2} \times p \times q},
$$


where $N$ is the population size, $p=1-q$ represents the yes/no categories, $z_{\alpha / 2}$ is CDF of normal distribution and finally $\varepsilon$ is the error term. Since we have $p=0.5, z_{\alpha / 2}=1.96$ and $N=800$, the number of sample size is calculated as $n=260$. The study uses structural equation modeling (SEM) to examine the hypotheses of the propsoed method.

\section{The results}

In this section, we present details of our findings on testing various hypotheses of the survey. Fig. 1 shows details of the results of SEM implementation.

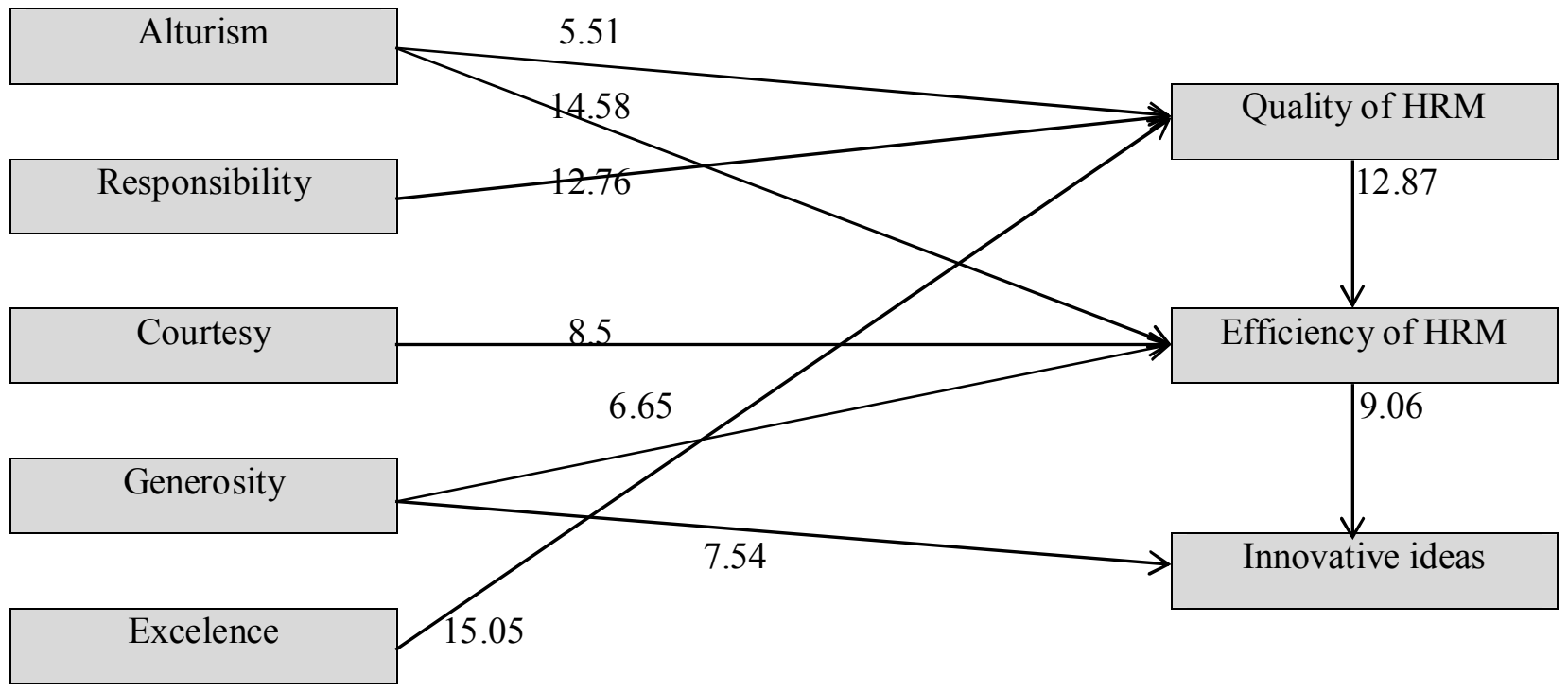

Fig. 1. The results of t-student values of SEM implementation

Based on the results of Fig. 1, we may examine different hypotheses of the survey.

\subsection{The first hypothesis: The effect of responsibility on HRM}

The first hypothesis of the survey investigates the effects of having good sense of responsibility on building an appropriate HRM. In our survey, there was a positive and meaningful relationship between these two components $(\beta=0.49$, t-value=13.76, Sig. $<0.05)$, which confirms the first hypothesis of the survey.

\subsection{The second hypothesis: The effect of generosity on HRM}

The first hypothesis of the survey studies the effects of being generous on having effective HRM. In our survey, there was a positive and meaningful relationship between these two components $(\beta=0.68$, $\mathrm{t}$-value $=6.65$, Sig. $<0.05$ ), which confirms the second hypothesis of the survey.

\subsection{The third hypothesis: The effect of courtesy on HRM}

The third hypothesis of the survey looks at the effects of having good courtesy on building an efficient HRM. In our survey, there was a positive and meaningful relationship between these two components $(\beta=0.50, \mathrm{t}-\mathrm{value}=8.5$, sig $<0.05)$, which confirms the third hypothesis of the survey.

\subsection{The fourth hypothesis: The effect of courtesy on innovative HRM}

The fourth hypothesis of the survey studies at the impacts of having good courtesy on building an innovative HRM through efficient HRM. In our survey, there was a positive and meaningful 
relationship between these two components $(\beta=0.50$, t-value $=7.54$, sig $<0.05)$, which confirms the fourth hypothesis of the survey.

In summary, the study has confirmed all hypotheses of the survey and the effects of different factors are ranked using Freedman test and the results have indicated that courtesy is the most important factor $($ Mean rank $=5.85)$, followed by generosity (Mean rank $=5.76)$ and responsibility (Mean rank $=5.42)$.

\section{Conclusion}

In this paper, we have presented an empirical investigation to study the effects of various factors influencing on the success of HRM in auto industry. The study has confirmed that three factors, courtesy, generosity and responsibility have influenced positively on development of human resources management and they could help employees build innovative ideas. The results of this study are consistent with findings of Adebayo (2005), Aslan and Şendoğdu (2012) and Vardaman et al. (2014) in terms of ethical issues.

\section{Acknowledgement}

The authors would like to thank the people who cordially participated in our survey and contributed to our results.

\section{References}

Adebayo, D. O. (2005). Ethical attitudes and prosocial behaviour in the Nigeria police: Moderator effects of perceived organizational support and public recognition. Policing: An International Journal of Police Strategies \& Management, 28(4), 684-705.

Aslan, Ş, \& Şendoğdu, A. (2012). The mediating role of corporate social responsibility in ethical leader's effect on corporate ethical values and behavior. Procedia - Social and Behavioral Sciences, 58(12), 693-702

Cash, A.C. (2012). Corporate social responsibility and petroleum development in sub-Saharan Africa: The case of Chad. Resources Policy, 37(2), 144-151.

Campbell, B. (2012). Corporate Social Responsibility and development in Africa: Redefining the roles and responsibilities of public and private actors in the mining sector. Resources Policy, $37(2), 138-143$.

Vardaman, J.M., Gondo, M.B., Allen, D.G. (2014). Ethical climate and pro-social rule breaking in the workplace. Human Resource Management Review, 24(1), 108-118.

Van Buren III, H.J., Greenwood, M., \& Sheehan, C. (2011). Strategic human resource management and the decline of employee focus. Human Resource Management Review, 21(3), 209-219

Wells, D., \& Schminke, M. (2001). Ethical development and human resources training: an integrative framework. Human Resource Management Review, 11(1-2), 135-158

Yoon, C. (2009). The effects of organizational citizenship behaviors on ERP system success. Computers in Human Behavior, 25(2), 421-428. 